\title{
BMJ Open Venous thromboembolism in adults screened for sickle cell trait: a population-based cohort study with nested case-control analysis
}

\author{
Iain Little, Yana Vinogradova, Elizabeth Orton, Joe Kai, Nadeem Qureshi
}

To cite: Little I,

Vinogradova $\mathrm{Y}$, Orton $\mathrm{E}$, et al. Venous thromboembolism in adults screened for sickle cell trait: a population-based cohort study with nested case-control analysis. BMJ Open 2017;7:e012665. doi:10.1136/bmjopen-2016012665

- Prepublication history and additional material is available. To view please visit the journal (http://dx.doi.org/ 10.1136/bmjopen-2016012665).

Received 16 May 2016 Revised 31 January 2017 Accepted 3 February 2017

CrossMark

Division of Primary Care, University of Nottingham, Nottingham, UK

Correspondence to Dr Nadeem Qureshi; nadeem.qureshi@nottingham. ac.uk

\section{ABSTRACT}

Objective: To determine whether sickle cell carriers ('sickle cell trait') have an increased risk of venous thromboembolism (VTE).

Design: Cohort study with nested case-control analysis.

Setting: General population with data from 609 UK general practices in the Clinical Practice Research Datalink (CPRD).

Participants: All individuals registered with a CPRD general practice between 1998 and 2013, with a medical record of screening for sickle cell between 18 and 75 years of age.

Main outcomes measures: Incidence of VTE per 10000 person-years (PY) among sickle cell carriers and non-carriers; and adjusted OR for VTE among sickle cell carriers compared with noncarriers.

Results: We included 30424 individuals screened for sickle cell, with a follow-up time of 179503 PY, identifying 55 VTEs in 6758 sickle cell carriers and 125 VTEs in 23666 non-carriers. VTE incidence among sickle cell carriers (14.9/10 $000 \mathrm{PY} ; 95 \% \mathrm{Cl} 11.4$ to 19.4) was significantly higher than non-carriers (8.8/ $10000 \mathrm{PY} ; 95 \% \mathrm{Cl} 7.4$ to 10.4). Restricting analysis to confirmed non-carriers was non-significant, but performed on a small sample. In the case-control analysis (180 cases matched to 1775 controls by age and gender), sickle cell carriers remained at increased risk of VTE after adjusting for body mass index, pregnancy, smoking status and ethnicity (OR 1.78, $95 \% \mathrm{Cl} 1.18$ to $2.69, \mathrm{p}=0.006$ ), with the greatest risk for pulmonary embolism (PE) (OR 2.27, 95\% Cl 1.17 to $4.39, \mathrm{p}=0.011$ ).

Conclusions: Although absolute numbers are small, in a general population screened for sickle cell, carriers have a higher incidence and risk of VTE, particularly $\mathrm{PE}$, than non-carriers. Clinicians should be aware of this elevated risk in the clinical care of sickle cell carriers, or when discussing carrier screening, and explicitly attend to modifiable risk factors for VTE in these individuals. More complete primary care coding of carrier status could improve analysis.
Strengths and limitations of this study

- The study used a large primary care database representative of the UK population.

- The database was interrogated over a 25-year time period, and included a large number of individuals screened for sickle cell.

- The findings from the main cohort study were consolidated by a nested case-control study.

- In the primary care database, there is limited recording of non-carrier status and ethnicity.

- No external source of data was available to verify carrier status and outcomes.

\section{INTRODUCTION}

Sickle cell disease (SCD) is a group of recessively inherited haemoglobin disorders causing anaemia, vascular occlusion and increased venous thromboembolism (VTE). ${ }^{1}$ People with sickle cell trait (SCT) are carriers who inherit one sickle haemoglobin gene and one normal haemoglobin gene. There are an estimated 300 million individuals worldwide with SCT, with the highest frequency of carriage in people of African or Middle Eastern origin, with increased rates among those of Mediterranean descent. ${ }^{2}{ }^{3}$ There are at least 240000 people with SCT in England, and an estimated 4 million individuals in the USA. ${ }^{4}$

SCT has important implications for genetic reproductive risk to offspring but is otherwise considered relatively harmless to the individual's health, manifesting no complications of SCD itself other than, rarely, in situations of severe dehydration or hypoxia such as at high altitude. ${ }^{6}$ However, concerns about other morbidity and mortality associated with being a sickle cell carrier have long been debated. These include reports of sudden exercise-related death in military recruits and 
college sportsmen. ${ }^{7-10}$ The US National Collegiate Athletic Association's mandatory SCT screening programme for student athletes has provoked considerable controversy about whether this will improve outcomes, while also leading to discrimination and confusion. ${ }^{411} 12$ Recently, SCT has also been shown to be associated with chronic kidney disease. ${ }^{13}$

Arguably of greater relevance to all people who are sickle cell carriers and routine clinical practice are reports of increased risk of VTE. ${ }^{2}{ }^{14-16}$ However, rather than draw from the general population, these studies have involved selected samples already at higher risk of thromboembolism, such as hospitalised patients, ${ }^{15} 1718$ individuals in the peripartum period ${ }^{19}$ or have focused solely on African-Americans. ${ }^{16}{ }^{20}$ For example, in a casecontrol study of hospitalised African-Americans, the likelihood of VTE was approximately twice as high among those with SCT compared with non-carriers. ${ }^{15}$ However, more robust evidence on potential morbidity related to SCT in the wider general population is lacking.

In the UK, as far back as 1993, policymakers have recommended that primary care should screen patients opportunistically for SCT to identify potential genetic reproductive risk, for example, when they registered with a practice. ${ }^{21}$ The identification of SCT has greater significance now that several countries are establishing national population screening programmes for sickle cell. For example, since 2003, women in the UK have been routinely offered screening for sickle cell carrier status in pregnancy to better inform reproductive risk assessment, and all newborn babies are offered screening for SCD (which also identifies carriers). ${ }^{22}$ Similar newborn screening has been offered in New York State since 1975, with universal newborn sickle cell screening throughout the USA since $2006 .{ }^{23}$ These screening programmes are increasing the number of people identified with SCT in general populations and so achieving a better understanding of possible implications for their health is needed. The aim of this study therefore was to investigate potential associations between SCT and risk of VTE in the general population.

\section{METHODS}

\section{Study design and setting}

We conducted an open cohort study with nested casecontrol analysis of patient medical data from the UK's Clinical Practice Research Datalink (CPRD). In the UK, the general practitioner holds the lifelong medical record of all patients registered with their practice and $98 \%$ of the UK population is registered with a general practitioner. ${ }^{24}$ The CPRD contains an anonymised copy of these medical records for more than 12 million patients from over 600 general practices across the UK, comprising one of the largest sources of continuous medical and prescribing data in the UK. ${ }^{25}$ Patient data regarding primary, secondary and tertiary healthcare usage are documented in an electronic health record using the Read code classification system, based on the International Classification of Diseases V.10. It includes prescription data, medical diagnoses, symptoms, test results, treatments and records of secondary care attendance. Patient records in CPRD are representative of the UK population ${ }^{26} 27$ and of good quality for epidemiological research, including for VTE events. ${ }^{28-30}$

\section{Study participants}

Study participants were registered with 609 CPRD practices between February 1988 and May 2013 and had been screened for sickle cell between age 18 and 75 years. Participants entered the study at the latest of 1 January of the year of their 18 birthday, their date of practice registration or the date that the practice attained the recognised data quality standard for CPRD. Participants were followed up until the earliest of the 1 January of the year of their 75 birthday, date of death, date of transfer out from the practice, the last collection date of data from the practice or the occurrence date of the first VTE event.

Patients were classified as having SCT if they had a diagnostic code for SCT or recorded laboratory test result confirming carrier status (with or without a medical code entry indicating screening for sickle cell). For the main analysis, patients were classified as not having SCT (non-carriers) if they had a medical code indicating sickle cell screening at any age and had no result recorded in their medical records, or had a medical code or test results indicating non-carrier status. A sensitivity analysis was undertaken that only included patients with confirmed non-carrier status, thus excluding individuals who did not have a diagnostic code or recorded laboratory test result for non-carrier status. Patients were considered to have had a VTE if they had a validated diagnostic medical code for VTE in their record during the observational period (February 1988May 2013). ${ }^{29}$ We included only the first occurrence of VTE between the ages of 18 and 75 years while registered in a CPRD practice. We excluded patients with documented VTE prior to cohort entry or with a history of anticoagulant therapy more than 6 weeks prior to the date of VTE as this could indicate a previous VTE. Individuals with a medical diagnosis of SCD were excluded from the study. Code lists for VTE, sickle cell screening, carrier and non-carrier status are in online supplementary material.

\section{Main outcome measures}

Our main outcome for the cohort analysis was the incidence rate of VTE per 10000 person-years (PY) among carriers and non-carriers. In the nested case-control analysis, our main outcome was the adjusted OR for VTE among carriers compared with non-carriers.

\section{Cohort analysis}

The cohort was described by frequencies and percentages of carriers and non-carriers in groups defined by 
gender, ethnicity and socioeconomic status. The Townsend Deprivation Index of material deprivation was used to assess the socioeconomic profile of the cohort. ${ }^{31}$

Incidence rates of first VTE were calculated by dividing the number of new cases by PY of follow-up. Incidence rates for subcategories of VTE were also calculated, including deep venous thrombosis (DVT) and pulmonary embolism (PE) and other, rarer VTE, such as retinal vein thrombosis and cerebral venous thrombosis. We used the Mantel-Haenszel method to compare incidence rates between carrier and non-carrier groups. Data management and statistical analyses were performed using Stata V.13.

\section{Nested case-control study}

We undertook a nested case-control study to investigate the association between VTE outcome and carrier status, taking into account potential confounding factors. The case-control study was based on the underlying cohort where matched controls were randomly selected from all remaining participants at risk, including potential future cases. $^{32}$ Estimates obtained from nested case-control studies and from underlying cohorts have been shown to be similar. ${ }^{33}$ This design also allowed us to use data for confounding factors ascertained at the closest time before the VTE date, thus simplifying the analysis of time-dependent exposures.

The controls were matched by year of birth and gender and allocated an index date, which was the VTE diagnosis date for their matched case. Controls with anticoagulant therapy at any time before the index date were excluded from the analysis.

\section{Case-control analysis}

We used conditional logistic regression to estimate unadjusted and adjusted ORs and 95\% CIs for VTE in carriers compared with non-carriers. For the multivariable analysis, we matched for age and sex, and adjusted for a priori confounders: ethnicity, smoking status, body mass index (BMI) and pregnancy.

Validation of VTE events recorded in primary care has demonstrated that the vast majority are supported by relevant hospital investigations or death certification. ${ }^{29}$ However, to account for any potential misclassification of cases and controls by relying on diagnostic recording of VTE in primary care records, we undertook a subgroup analysis using a more stringent definition of VTE diagnosis, in which VTE occurrence was supported by one of the following: a documented prescription for warfarin or low-molecular weight heparin within 3 months of the date of diagnosis; or evidence of attendance at a clinic for treatment with anticoagulants within 3 months of diagnosis; or death within 1 month of diagnosis. ${ }^{34} 35$

We included ethnicity, pregnancy, BMI and smoking status as covariates. We selected these because within the UK, minority ethnic groups are more likely to be offered sickle cell testing, risk of first VTE in pregnant women is at least sixfold, ${ }^{36} 37$ obesity is associated with a 2-3 times increased risk of $\mathrm{VTE}^{3839}$ and smoking with a 1.5 times increased risk. ${ }^{40}$ B1 $\mathrm{BMI}$ and smoking are routinely recorded in UK primary care electronic health records. ${ }^{42}{ }^{43}$ Smoking status and BMI data were extracted using the closest record prior to the index date. Smoking status was categorised into: current smokers, ex-smokers and non-smokers. BMI was defined as weight (in kilograms) divided by the square of height (in metres), and categorised into <25, 25-29 and $\geq 30$. Ethnicity was extracted from primary care records or, where not available, from linked hospital electronic health records (HES) and categorised as: White; Asian (comprising ethnic groups from the Indian subcontinent and China); Black (indicative of African ancestry); Other (including mixed ethnicity). Ethnicity was self-reported by patients attending General Practice or Hospital, and was grouped by investigators. Pregnancy included the first 3 months after delivery and was defined using pregnancy codes and the estimated conception date of delivery minus 280 days or delivery date minus gestational age if recorded. ${ }^{44}$ Since pregnancy and the postpartum period is associated with increased risk of VTE, ${ }^{45}$ we undertook a sensitivity analysis removing pregnant women from the analysis. Subgroup analysis of VTE and SCT in Black people was also undertaken to allow direct comparison with the previous literature. ${ }^{15} 1618$

To retain the statistical power and obtain unbiased results, all observations were included in the analysis. Chained equations were used to impute missing values for the covariates. ${ }^{46}$ Ten imputed sets were generated and the imputation model: matching variables (age and gender); exposure (carrier, non-carrier); outcome (case or control); covariates (pregnancy, logarithm of BMI, smoking status and ethnicity); UK region (because the ethnicity profile differs by regions); index year. ${ }^{47}$ The results from the imputed sets were combined using Rubin's rules. ${ }^{46}$ To ensure the assumption that the data were missing at random, we ran a sensitivity analysis on patients with complete data.

\section{Patient involvement}

The study was a retrospective, quantitative, observational study using information routinely collected by general practices and a similar linked source of census data. The design and the development of outcome measures were necessarily technical, based in part on earlier publications and medical expertise within the team, but primarily on examination of available data in order to maximise inclusiveness and length of study period. As such, patients were not involved in any of these aspects. However, as well as dissemination through this publication, we are working with sickle cell patient groups to produce lay summaries describing the research and its results. With respect to the use of the CPRD database, the CPRD Group has ethical approval from a National Research Ethics Service Committee (NRES) for all research not including patient involvement and using anonymised data. 


\section{RESULTS}

\section{Cohort analysis}

During the study period, 45746 individuals had a record of sickle cell screening in their medical records. After exclusions (figure 1), the cohort analysis included 30424 individuals; 6758 individuals with SCT (carriers) and 23666 without SCT (non-carriers). Overall, 82.5\% of individuals were women, with a higher proportion in the non-carrier group than the carrier group $(86.9 \%$ vs $67.3 \%$, respectively) (table 1). Ethnicity was recorded for more than $80 \%$ of the study population and of those with recorded ethnicity, $53.4 \%$ of the carrier group and $15.8 \%$ of the non-carrier group were Black.

One hundred and eighty VTEs were identified within a total follow-up time of 179503 PY. The median follow-up time was 3.71 years in the carrier group and 4.68 years in the non-carrier group. The incidence of VTE was 14.9 (95\% CI 11.4 to 19.4) per 10000 PY in carriers, and 8.8 (95\% CI 7.4 to 10.4 ) per $10000 \mathrm{PY}$ in non-carriers (table 2). Considering VTE subgroups, the difference in incidence rates was greatest for PEs and not significant for DVT. Sensitivity analysis with confirmed non-carriers identified low event rates in this subgroup, leading to wide CIs but showed a consistent pattern of results to the main analysis (see online supplementary table S1).

\section{Nested case-control analysis}

A total of 180 cases were matched to 1775 controls by gender and year of birth. Cases and controls had similar profiles with the majority of participants being women (table 3). The proportion of obese patients was higher among cases $(31.1 \%$ compared with $20.6 \%$ of controls, $\mathrm{p}<0.001$ ), and women were more likely to be pregnant in cases $(29.4 \%$ of female cases) than in controls $(16.4 \%$ of female controls).

After adjusting for a priori confounders (see online supplementary table S2), carriers were 1.78 times more likely to have a VTE than non-carriers (OR 1.78, 95\% CI 1.18 to 2.69) and the odds of $\mathrm{PE}$ in carriers increased even further (OR 2.27, 95\% CI 1.17 to 4.39) (table 4). The odds of DVT were increased in carriers, although this was not significant (OR $1.43,95 \%$ CI 0.79 to 2.59 ).

When we restricted the case definition of VTE to include cases with a diagnostic medical code for VTE, supported by a record of anticoagulant therapy, clinic attendance or death, there was a more than twofold increased odds of VTE in carriers (OR 2.71, 95\% CI 1.52 to 4.83). After removal of pregnant women from the cohort, the odds of VTE in carriers compared with non-carriers remained consistent at $1.80(95 \%$ CI 1.15 to 2.83$)$.
Figure 1 Flow chart of patients in the cohort study. CPRD, Clinical Practice Research Datalink; VTE, venous thromboembolism.

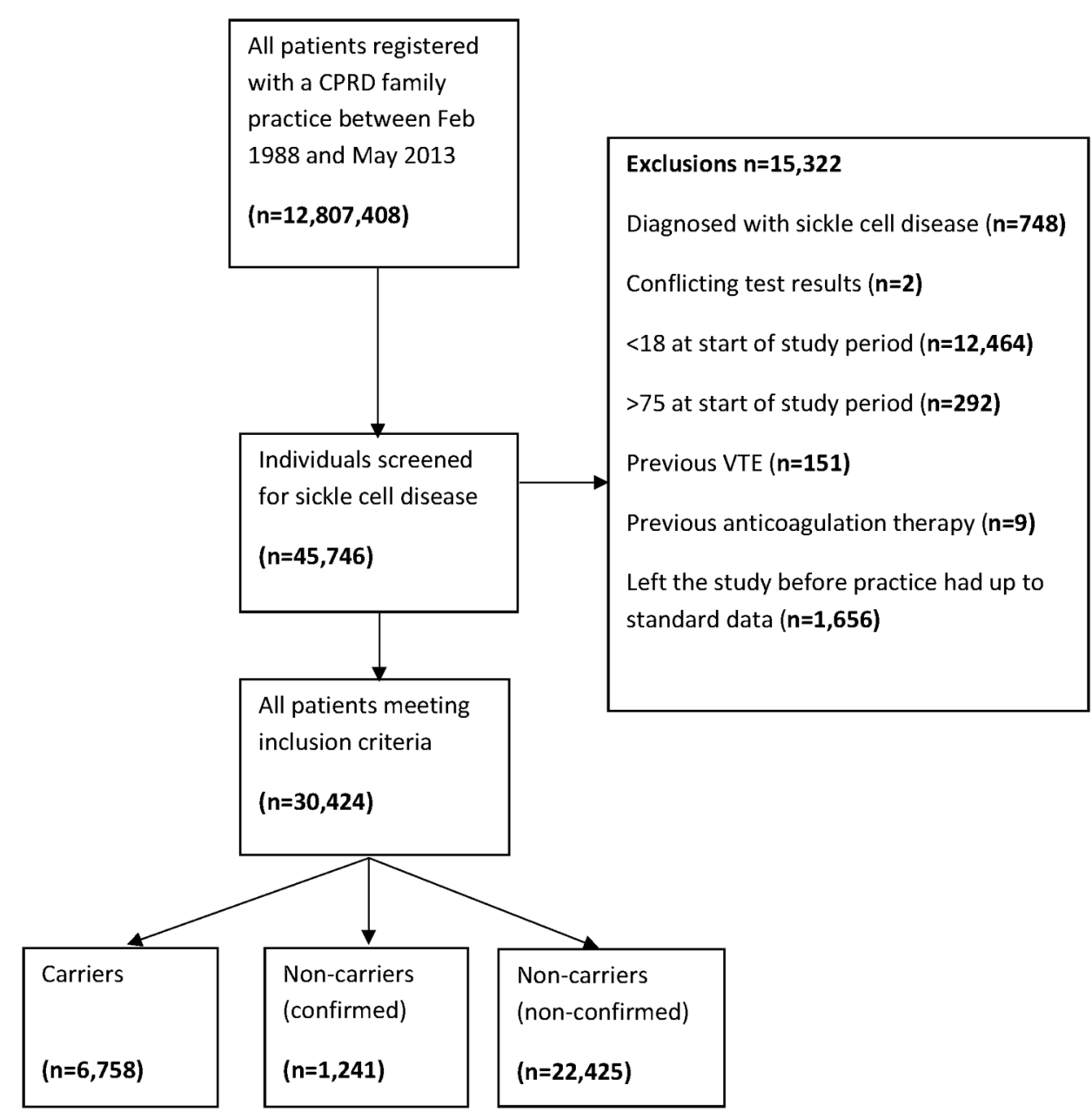


Table 1 Characteristics of the study population and numbers and proportions of carriers and non-carriers for each category

\begin{tabular}{|c|c|c|c|}
\hline Demographic characteristics & Whole cohort & Carriers & Non-carriers \\
\hline Total number of patients & 30424 & 6758 & 23666 \\
\hline \multicolumn{4}{|l|}{ Age at study entry } \\
\hline Median (IQ range) & $28(22,36)$ & $32(25,41)$ & $28(22,34)$ \\
\hline \multicolumn{4}{|l|}{ Age at SCD test } \\
\hline Median (IQ range) & $29(23,36)$ & $28(19,36)$ & $30(24,35)$ \\
\hline \multicolumn{4}{|l|}{ Gender } \\
\hline Male (\%) & $5322(17.5)$ & 2213 (32.7) & $3109(13.1)$ \\
\hline Female (\%) & $25102(82.5)$ & 4545 (67.3) & 20557 (86.9) \\
\hline \multicolumn{4}{|l|}{ Ethnicity } \\
\hline White (\%) & $8678(28.5)$ & $484(7.2)$ & $8194(34.6)$ \\
\hline Black (\%) & $7343(24.1)$ & 3608 (53.4) & 3735 (15.8) \\
\hline Asian (\%) & 3408 (11.2) & $228(3.4)$ & $3180(13.4)$ \\
\hline Other (\%) & $5377(17.7)$ & $662(9.8)$ & 4715 (19.9) \\
\hline Not recorded (\%) & 5618 (18.5) & 1776 (26.3) & $3842(16.2)$ \\
\hline \multicolumn{4}{|l|}{ Socioeconomic status } \\
\hline Quintile 1 (least deprived) & $1784(8.3)$ & $325(4.8)$ & $1459(6.2)$ \\
\hline Quintile 2 & 1998 (9.3) & $386(5.7)$ & $1612(6.8)$ \\
\hline Quintile 3 & 2417 (11.3) & $602(8.9)$ & $1815(7.7)$ \\
\hline Quintile 4 & 4125 (19.2) & 1179 (17.4) & 2946 (12.4) \\
\hline Quintile 5 (most deprived) & $6876(32.0)$ & 2254 (33.4) & $4622(19.5)$ \\
\hline Missing & 4278 (19.9) & 2012 (29.8) & $11212(47.4)$ \\
\hline
\end{tabular}

Table 2 Incidence rates per 10000 person-years (PY) for venous thromboembolism (VTE), deep vein thrombosis (DVT), pulmonary embolism (PE) and other VTEs by carrier status

\begin{tabular}{|c|c|c|c|c|c|c|}
\hline & \multicolumn{2}{|l|}{ Carrier } & \multicolumn{2}{|c|}{ Non-carriers } & \multirow[b]{2}{*}{$\begin{array}{l}\text { Incidence rate } \\
\text { ratio }(95 \% \mathrm{Cl})\end{array}$} & \multirow[b]{2}{*}{ p Value } \\
\hline & $\begin{array}{l}\text { Number of } \\
\text { events }\end{array}$ & $\begin{array}{l}\text { Incidence rate per } \\
10000 \mathrm{PY}(95 \% \mathrm{Cl})\end{array}$ & $\begin{array}{l}\text { Number of } \\
\text { events }\end{array}$ & $\begin{array}{l}\text { Incidence rate per } \\
10000 \mathrm{PY}(95 \% \mathrm{Cl})\end{array}$ & & \\
\hline VTE & 55 & 14.9 (11.4 to 19.4$)$ & 125 & 8.77 (7.35 to 10.4$)$ & 1.70 (1.24 to 2.33$)$ & 0.001 \\
\hline DVT only & 24 & 6.53 (4.37 to 9.74$)$ & 83 & 5.83 (4.70 to 7.23$)$ & $1.12(0.71$ to 1.76$)$ & 0.2 \\
\hline PE only & 26 & 7.07 (4.81 to 10.4$)$ & 36 & 2.53 (1.83 to 3.51$)$ & 2.79 (1.69 to 4.62$)$ & $<0.001$ \\
\hline Other VTE & 5 & $1.36(0.57$ to 3.28$)$ & 6 & $0.42(0.19$ to 0.94$)$ & 3.23 (0.99 to 10.6$)$ & 0.041 \\
\hline
\end{tabular}

There were 27 VTE events in the subgroup of 7343 Black patients. The incidence rate of VTE was 12.9 per 10000 PY; 15.5 per $10000 \mathrm{PY}$ in carriers and 10.6 per $10000 \mathrm{PY}$ in non-carriers (incidence rate ratio $1.45,95 \%$ CI 0.82 to $2.59, \mathrm{p}=0.2)$. In the case-control analysis, 47 cases were matched by age and gender to 418 controls. After adjusting for covariates, the VTE risk associated with SCT carrier in this subgroup was in line with the main analysis (OR $1.73,95 \%$ CI 0.91 to $3.32, \mathrm{p}=0.096$ ).

\section{DISCUSSION}

In a large general population cohort screened for sickle cell over a 25-year period, we have found SCT was associated with a significantly increased likelihood of VTE, in particular, PE.

The findings from the cohort study were consolidated by a nested case-control study. ${ }^{48}$ Analysis of VTE based solely on medical code recording does include the potential for false-positive diagnoses. However, $84 \%$ of VTEs reported in primary care have been validated through hospital records or death records. ${ }^{29}$ Our study findings were consistent when a more stringent definition of VTE (combining evidence from medical diagnoses, drug therapies and/or clinic attendance) was used.

\section{Strengths and limitations of the study}

A major strength of this study is the investigation and confirmation of a significant association between SCT and VTE in a very much larger, more socially and ethnically diverse, general population than previous studies. The CPRD contain data from patients that are considered representative of the general UK population. ${ }^{49}$ Our cohort analysis included more than 30000 individuals screened for sickle cell, with almost 7000 carriers and over 23000 non-carriers, with an incidence of VTE observed over nearly 180000 years of person time. We also note the VTE incidence in non-carriers is similar to that reported in the UK general population. ${ }^{48}$

We recognise that only people who had screening and/or testing documented in their medical record 
Table 3 Characteristics of cases and controls: frequencies and proportions

\begin{tabular}{|c|c|c|c|}
\hline & $\begin{array}{l}\text { Cases frequency (\%) } \\
n=180\end{array}$ & $\begin{array}{l}\text { Controls frequency (\%) } \\
n=1775\end{array}$ & Adjusted ORs $(95 \% \mathrm{Cls})^{\star}$ \\
\hline \multicolumn{4}{|l|}{ Sex } \\
\hline Male & $42(23.3)$ & $409(23.0)$ & \\
\hline Female & $138(76.7)$ & $1366(77.0)$ & \\
\hline \multicolumn{4}{|c|}{ Age at first VTE/index date } \\
\hline $18-34$ & $83(46.1)$ & $828(46.6)$ & \\
\hline $35-54$ & $62(34.4)$ & $615(34.6)$ & \\
\hline $55-74$ & 35 (19.4) & $332(18.7)$ & \\
\hline \multicolumn{4}{|l|}{ Ethnicity } \\
\hline White & $59(32.8)$ & $518(29.2)$ & Reference \\
\hline Black & $47(26.1)$ & $431(24.3)$ & $0.74(0.47$ to 1.17$)$ \\
\hline Asian & $14(7.8)$ & $176(9.9)$ & $0.82(0.41$ to 1.63$)$ \\
\hline Other & $32(17.8)$ & $299(16.8)$ & $0.89(0.56$ to 1.40$)$ \\
\hline Not recorded & $28(15.6)$ & $351(19.8)$ & \\
\hline \multicolumn{4}{|l|}{ Smoking status } \\
\hline Non-smokers & $104(57.8)$ & $1058(59.6)$ & Reference \\
\hline Ex-smokers & 34 (18.9) & 275 (15.5) & $1.18(0.76$ to 1.85$)$ \\
\hline Smokers & $31(17.2)$ & $331(18.6)$ & 1.05 (0.67 to 1.63$)$ \\
\hline Not recorded & $11(6.1)$ & $111(6.3)$ & \\
\hline \multicolumn{4}{|l|}{$\mathrm{BMI}$} \\
\hline BMI mean (SD) & $28.7(6.0)$ & $26.5(5.5)$ & \\
\hline$<25 \mathrm{~kg} / \mathrm{m}^{2}$ & $44(24.4)$ & $694(39.1)$ & Reference \\
\hline $25-29 \mathrm{~kg} / \mathrm{m}^{2}$ & 59 (32.8) & $479(27.0)$ & 2.05 (1.30 to 3.23$)$ \\
\hline $30+\mathrm{kg} / \mathrm{m}^{2}$ & $56(31.1)$ & $365(20.6)$ & 2.69 (1.67 to 4.33$)$ \\
\hline Not recorded & $21(11.7)$ & $237(13.4)$ & \\
\hline \multicolumn{4}{|l|}{ Pregnant } \\
\hline No & $127(70.6)$ & $1484(83.6)$ & Reference \\
\hline Yes & $53(29.4)$ & $291(16.4)$ & 1.45 (1.25 to 1.69$)$ \\
\hline
\end{tabular}

Table 4 Unadjusted and adjusted ORs of thrombotic events in patients with sickle cell trait (SCT), compared with patients without SCT, main and subgroup analyses

\begin{tabular}{|c|c|c|c|c|c|}
\hline & Cases & Controls & OR $^{*}$ & Adjusted OR† & p Value \\
\hline \multicolumn{6}{|l|}{ Main analysis } \\
\hline \multicolumn{6}{|l|}{ VTE } \\
\hline Non-carrier & 125 & 1369 & 1.00 & 1.00 & - \\
\hline Carrier & 55 & 406 & 1.55 (1.09 to 2.21$)$ & 1.78 (1.18 to 2.69$)$ & 0.006 \\
\hline \multicolumn{6}{|l|}{ DVT only } \\
\hline Non-carrier & 83 & 841 & 1.00 & 1.00 & - \\
\hline Carrier & 24 & 207 & $1.18(0.71$ to 1.95$)$ & $1.43(0.79$ to 2.59$)$ & 0.2 \\
\hline \multicolumn{6}{|c|}{ (1) } \\
\hline Non-carrier & 36 & 449 & 1.00 & 1.00 & - \\
\hline Carrier & 26 & 170 & 2.09 (1.17 to 3.72$)$ & 2.27 (1.17 to 4.39$)$ & 0.011 \\
\hline \multirow{2}{*}{\multicolumn{6}{|c|}{$\begin{array}{l}\text { Subgroup analysis } \\
\text { VTE definition included anticoagulant therapy, clinic attendance or death }\end{array}$}} \\
\hline & & & & & \\
\hline Non-carrier & 60 & 725 & 1.00 & 1.00 & - \\
\hline Carrier & 36 & 223 & $2.20(1.36$ to 3.57$)$ & 2.71 (1.52 to 4.83$)$ & 0.001 \\
\hline
\end{tabular}

were included, potentially missing others in the population who had been screened for sickle cell. However, the introduction of universal sickle cell and thalassaemia antenatal carrier screening in the UK in 2003 will have improved recording, with universal screening across the entire antenatal population in areas with higher prevalence of SCD (more than 1.5 per 10000 births). ${ }^{50}$ This is reflected in the study population, which, as expected, was mostly screened around reproductive age with proportionally more women, while still representative of the 
broad ethnic and social diversity of the UK general population.

The majority of people had a record of screening but no result recorded and these participants were assumed to be non-carriers in our main analysis, as this would be consistent with clinical practice. However, some with no results recorded may have been carriers. The presence of carriers in the unconfirmed non-carriers (no test) group would reduce the effect size of the main analysis. Further, GPs are more likely to document carrier state than non-carrier state introducing recall bias. Restricting participants to only those with documented carrier and non-carrier status resulted in incidence rates and incidence rate ratios that were consistent with the main analysis, although underpowered due to the restricted number of events. We also only used patient data that were considered to be of sufficient quality (in terms of completeness and accuracy) as determined by CPRD (ie, identified as 'up to standard' within the database). However, we were only able to take account of confounding factors that are recorded in the electronic health record. Similarly, while free-text information on diagnostic imaging is inconsistent and not accessible to researchers in electronic primary care records, the prevalence of $\mathrm{PE}$ in the carrier group could potentially reflect ascertainment bias, if, for example, clinicians had a lower index of suspicion for lung problems in carriers, with more frequent diagnostic imaging.

\section{Comparison with recent studies}

Our findings are consistent with previous North American studies in demonstrating a relationship between SCT and VTE, but confirm this not only in a much larger general population sample but also across socioeconomic groups and ethnicities. Based on our subgroup and adjusted analyses, the difference in VTE incidence rates could not be attributed to difference in the ethnicity of carriers and non-carriers in our study. Our results are also consistent with previous observational studies with smaller or more selected populations. $^{15} 1618{ }^{20}$ Similar to our findings, Austin et $a l^{15}$ reported a higher risk of PE among hospitalised black Americans with SCT, with no increased risk of DVT in carriers compared with non-carriers. An earlier retrospective cohort study of hospitalised black men found PE occurring in $2.2 \%$ of carriers compared with $1.5 \%$ in non-carriers, though diagnosis of PE was based solely on clinical criteria. ${ }^{18}$ Recent cohort studies, again of African-Americans only, have reported no increased overall risk of VTE but up to a twofold increased risk of PE. ${ }^{16}{ }^{20}$ The possible causes for this increased risk of VTE remain unclear but may, in part, be related to increased coagulation activity found in SCT. ${ }^{51}$ Ideally, future research should explore the relationship between SCT and VTE in a prospective birth cohort systematically offered neonatal screening for sickle cell with carrier and non-carrier state accurately documented. If primary care records are to be used in future research, the coding of non-carrier status needs to be improved, for example, through direct coding of carrier status when results are transferred electronically to primary care records from pathology laboratories.

\section{Implications for clinical practice}

Currently, individuals identified with SCT are advised that their carrier state is relatively harmless to their health, with caution required only in unusual conditions of severe dehydration or hypoxia such as extreme exertion, anaesthesia or high altitude. Although the absolute numbers of VTE events were small, our results indicate that clinicians should make patients with SCT aware of their increased risk of VTE and stress the particular importance of attending to modifiable risk factors, such as obesity and smoking. Compared with other conventional risk factors, the risk of VTEs with carrier status is similar to pregnancy, obesity and prolonged bed rest. ${ }^{36}$ The evidence may now be sufficiently robust to consider SCT a significant non-modifiable risk factor in evaluating patients' VTE risk. In the clinical setting, this could facilitate modification of other coexistent risk factors of VTE, such as obesity and immobility.

In relation to sickle cell screening, identification of carrier status is perceived as useful to inform individuals about potential reproductive genetic risk-antenatally and among parents of newborns. ${ }^{52} 53$ The current finding of increased risk of VTE in sickle cell carriers adds a further dimension to the appropriate provision of information to patients in such screening contexts. Given the experience of African-American communities in the recent past, caution is needed to avoid stigmatisation and community anxiety ${ }^{115455}$ in advancing appropriate care of people with SCT. Previous researchers have observed the Black community, at genetic risk of sickle cell, are also disadvantaged in society. A situation exacerbated by racism. ${ }^{56}$ Such issues also deserve further consideration. However, we also note our findings are drawn from a large, socially and ethnically diverse general population with SCT. Thus, this study's implications for clinical practice are not confined to a particular ethnic community, but rather apply to all.

Acknowledgements The authors thank Drs Vence Bonham and Sarah Donohue for their expert advice at the conception of the study. There have been no conference presentations of this study.

Contributors NQ, JK, EO and YV are responsible for study conception and design. All authors are responsible for acquisition, analysis or interpretation of data. IL is responsible for drafting of the manuscript. NQ, JK, EO and YV are responsible for critical revision of the manuscript for important intellectual content. YV and IL are responsible for statistical analysis. NQ and JK obtained funding. All authors are responsible for administrative, technical or material support. NQ and EO are responsible for study supervision. All authors had full access to the data in the study and can take full responsibility for the integrity of the data and the accuracy of the data analysis.

Funding This research received no specific grant from any funding agency in the public, commercial or not-for-profit sectors.

Competing interests None declared. 
Ethics approval We obtained ethical approval from the CPRD Independent Scientific Advisory Committee of the UK Medicine and Healthcare products Regulatory Agency (protocol approval no. 13_097RA).

Provenance and peer review Not commissioned; externally peer reviewed.

Data sharing statement The authors confirm that, for approved reasons, some access restrictions apply to the data underlying the findings. Data are collected and owned and licensed by The Clinical Practice Research Datalink Group, The Medicines and Healthcare Products Regulatory Agency, 5th Floor 151 Buckingham Palace Road, Victoria, London SW1W 9SZ, UK. Contact +44 203080 6383. See https://www.cprd.com/dataAccess/default. asp\#OnlineDataGOLD

Open Access This is an Open Access article distributed in accordance with the Creative Commons Attribution Non Commercial (CC BY-NC 4.0) license which permits others to distribute, remix, adapt, build upon this work noncommercially, and license their derivative works on different terms, provided the original work is properly cited and the use is non-commercial. See: http:// creativecommons.org/licenses/by-nc/4.0/

\section{REFERENCES}

1. Serjeant GR, Serjeant BE. Sickle cell disease. 3rd edn. Oxford: Oxford University Press, 2001.

2. Tsaras G, Owusu-Ansah A, Boateng F, et al. Complications associated with sickle cell trait: a brief narrative review. Am J Med 2009;122:507-12. http://dx.doi.org/10.1016/j.amjmed. 2008.12.020

3. Modell B, Darlison M. Global epidemiology of haemoglobin disorders and derived service indicators. Bull World Health Organ 2008;86:480-7.

4. Jordan LB, Smith-Whitley K, Treadwell MJ, et al. Screening U.S. college athletes for their sickle cell disease carrier status. Am J Prev Med 2011;41(Suppl 4):S406-12.

5. England. PH. NHS Sickle Cell and Thallasaemia programme Fact and Figures. Secondary NHS Sickle Cell and Thallasaemia programme Fact and Figures. http://sct.screening.nhs.uk/statistics

6. Kark JA, Ward FT. Exercise and hemoglobin S. Semin Hematol 1994;31:181-225.

7. Kark JA, Posey DM, Schumacher HR, et al. Sickle-cell trait as a risk factor for sudden death in physical training. $N$ Engl J Med 1987;317:781-7.

8. Maron BJ, Doerer JJ, Haas TS, et al. Sudden deaths in young competitive athletes: analysis of 1866 deaths in the United States, 1980-2006. Circulation 2009;119:1085-92.

9. Harmon KG, Drezner JA, Klossner D, et al. Sickle cell trait associated with a RR of death of 37 times in National Collegiate Athletic Association football athletes: a database with 2 million athlete-years as the denominator. Br J Sports Med 2012;46: 325-30.

10. Jones SR, Binder RA, Donowho EM Jr. Sudden death in sickle-cell trait. N Engl J Med 1970;282:323-5.

11. Bonham VL, Dover GJ, Brody LC. Screening student athletes for sickle cell trait: a social and clinical experiment. $N$ Engl J Med 2010;363:997-9.

12. Carter B, Dyson SM. Actor network theory, agency and racism: the case of sickle cell trait and US athletics. Social Theory Health 2015;13:62-77

13. Naik RP, Derebail VK, Grams ME, et al. Association of sickle cell trait with chronic kidney disease and albuminuria in African Americans. JAMA 2014;312:2115-25.

14. Key NS, Derebail VK. Sickle-cell trait: novel clinical significance. Hematology Am Soc Hematol Educ Program 2010;2010:418-22.

15. Austin H, Key NS, Benson JM, et al. Sickle cell trait and the risk of venous thromboembolism among blacks. Blood 2007;110:908-12.

16. Bucknor MD, Goo JS, Coppolino ML. The risk of potential thromboembolic, renal and cardiac complications of sickle cell trait. Hemoglobin 2014;38:28-32.

17. Austin H, Lally C, Benson JM, et al. Hormonal contraception, sickle cell trait, and risk for venous thromboembolism among African American women. Am J Obstet Gynecol 2009;200:620.e1-3.

18. Heller $P$, Best WR, Nelson RB, et al. Clinical implications of sickle-cell trait and glucose-6-phosphate dehydrogenase deficiency in hospitalized black male patients. $N$ Engl J Med 1979;300:1001-5.
19. Pintova S, Cohen HW, Billett HH. Sickle cell trait: is there an increased VTE risk in pregnancy and the postpartum? PLoS ONE 2013;8:e64141.

20. Folsom AR, Tang W, Roetker NS, et al. Prospective study of sickle cell trait and venous thromboembolism incidence. J Thromb Haemost 2015;13:2-9.

21. Johnson AG. Report of a working party of the Standing Medical Advisory Committee on sickle cell, thalassaemia and other haemoglobinopathies. London: HMSO, 1993.

22. Ryan K, Bain BJ, Worthington D, et al. Significant haemoglobinopathies: guidelines for screening and diagnosis. Br J Haematol 2010;149:35-49.

23. Benson JM, Therrell BL Jr. History and current status of newborn screening for hemoglobinopathies. Semin Perinatol 2010;34:134-44.

24. NHS Digital. Attribution data set GP-registered populations 2010-2012. http://content.digital.nhs.uk/pubs/gpregpop10

25. Walley T, Mantgani A. The UK general practice research database. Lancet 1997;350:1097-9.

26. Lawrenson R, Williams T, Farmer R. Clinical information for research; the use of general practice databases. J Public Health Med 1999;21:299-304.

27. Crooks C. The epidemiology of upper gastrointestinal bleeding University of Nottingham, 2013.

28. Herrett E, Thomas SL, Schoonen WM, et al. Validation and validity of diagnoses in the General Practice Research Database: a systematic review. Br J Clin Pharmacol 2010;69:4-14.

29. Lawrenson R, Todd JC, Leydon GM, et al. Validation of the diagnosis of venous thromboembolism in general practice database studies. Br J Clin Pharmacol 2000;49:591-6.

30. Cardwell CR, Abnet CC, Cantwell MM, et al. Exposure to ora bisphosphonates and risk of esophageal cancer. JAMA 2010;304:657-63.

31. Morris R, Carstairs V. Which deprivation? A comparison of selected deprivation indexes. J Public Health Med 1991;13:318-26.

32. Etminan M. Pharmacoepidemiology II: the nested case-control study - a novel approach in pharmacoepidemiologic research. Pharmacotherapy 2004;24:1105-9.

33. Wacholder S. Bias in full cohort and nested case-control studies? Epidemiology 2009;20:339-40.

34. Grainge MJ, West J, Card TR. Venous thromboembolism during active disease and remission in inflammatory bowel disease: a cohort study. Lancet 2010;375:657-63.

35. Walker AJ, Card TR, West J, et al. Incidence of venous thromboembolism in patients with cancer-a cohort study using linked United Kingdom databases. Eur J Cancer 2013:49:1404-13.

36. Anderson FA Jr, Spencer FA. Risk factors for venous thromboembolism. Circulation 2003;107(Suppl 23):19-16.

37. Sultan AA, West J, Tata LJ, et al. Risk of first venous thromboembolism in and around pregnancy: a population-based cohort study. Br J Haematol 2012;156:366-73.

38. Cushman M. Epidemiology and risk factors for venous thrombosis. Semin Hematol 2007;44:62-9.

39. Huerta C, Johansson S, Wallander MA, et al. Risk factors and short-term mortality of venous thromboembolism diagnosed in the primary care setting in the United Kingdom. Arch Intern Med 2007:167:935-43.

40. Cheng YJ, Liu ZH, Yao FJ, et al. Current and former smoking and risk for venous thromboembolism: a systematic review and meta-analysis. PLoS Med 2013;10;e1001515.

41. Pomp ER, Rosendaal FR, Doggen CJM. Smoking increases the risk of venous thrombosis and acts synergistically with oral contraceptive use. Am J Hematol 2008;83:97-102.

42. Bhaskaran K, Forbes HJ, Douglas I, et al. Representativeness and optimal use of body mass index (BMI) in the UK Clinical Practice Research Datalink (CPRD). BMJ Open 2013;3:e003389.

43. Booth HP, Prevost AT, Gulliford MC. Validity of smoking prevalence estimates from primary care electronic health records compared with national population survey data for England, 2007 to 2011. Pharmacoepidemiol Drug Saf 2013;22:1357-61.

44. Vinogradova Y, Coupland C, Hippisley-Cox J. Use of combined oral contraceptives and risk of venous thromboembolism: nested case-control studies using the QResearch and CPRD databases. BMJ 2015;350:h2135

45. Sultan AA, Tata LJ, West J, et al. Risk factors for first venous thromboembolism around pregnancy: a population-based cohort study from the United Kingdom. Blood 2013;121:3953-61.

46. Royston P. Multiple imputation of missing values. Stata J 2004; 4:227-41.

47. Newgard CD, Lewis RJ. Missing data: how to best account for what is not known. JAMA 2015;314:940-1. 
48. Parker C, Coupland C, Hippisley-Cox J. Antipsychotic drugs and risk of venous thromboembolism: nested case-control study. BMJ 2010;341:641.

49. Herrett E, Gallagher AM, Bhaskaran K, et al. Data resource profile: Clinical Practice Research Datalink (CPRD). Int J Epidemiol 2015;44:827-36.

50. NHS England. NHS public health functions agreement 2015-16. Service specification no.18. NHS Sickle Cell and Thalassaemia Screening Programme. 10100 PIPP, 2014.

51. Westerman MP, Green D, Gilman-Sachs A, et al. Coagulation changes in individuals with sickle cell trait. Am J Hematol 2002;69:89-94.

52. Kai J, Ulph F, Cullinan $\mathrm{T}$, et al. Communication of carrier status information following universal newborn screening for sickle cell disorders and cystic fibrosis: qualitative study of experience and practice. Health Technol Assess 2009;13:1-82.

53. Locock L, Kai J. Parents' experiences of universal screening for haemoglobin disorders: implications for practice in a new genetics era. Br J Gen Pract 2008;58:161-8.

54. Whitten CF. Sickle-cell programming-an imperiled promise. N Engl J Med 1973;288:318-19.

55. Dyson S, Boswell G. Sickle cell and deaths in custody. London: Whiting and Birch, 2009.

56. Krieger N, Chen JT, Waterman PD, et al. The inverse hazard law: blood pressure, sexual harassment, racial discrimination, workplace abuse and occupational exposures in US low-income black, white and Latino workers. Soc Sci Med 2008;67:1970-81. 